\title{
Overall Energy Performance Assessment of a New Heat Blocking Coating
}

\author{
Deqi Wang ${ }^{1}$, Lin Lu ${ }^{* 2}$, Weilong Zhang ${ }^{3}$ \\ ${ }^{1}$ Department of Building Services Engineering, The Hong Kong Polytechnic University, 11 Yuk Choi Rd, \\ Hung Hom, Hong Kong \\ e-mail: dq.wang@polyu.edu.hk \\ ${ }^{2}$ Department of Building Services Engineering, The Hong Kong Polytechnic University, 11 Yuk Choi Rd, \\ Hung Hom, Hong Kong \\ e-mail: vivien.lu@polyu.edu.hk \\ ${ }^{3}$ Department of Building Services Engineering, The Hong Kong Polytechnic University, 11 Yuk Choi Rd, \\ Hung Hom, Hong Kong \\ e-mail: wei-long.zhang@polyu.edu.hk
}

Cite as: Wang, D., Lu, L., Zhang, W., Overall Energy Performance Assessment of a New Heat Blocking Coating,

J. sustain. dev. energy water environ. syst., (7)1, pp 1-12, 2019, DOI: https://doi.org/10.13044/j.sdewes.d6.0224

\begin{abstract}
In subtropical Hong Kong, clear glass is normally used as the translucent material for external windows of residential buildings, but it has poor heat insulation performance especially the tremendous solar heat gain in summer. To improve the thermal performance of conventional clear glass, a new heat blocking coating was developed. The coating can effectively absorb the near infrared radiation, so it can reduce the solar heat gain and therefore the energy use from air-conditioning systems. In this paper, the preparation of the heat blocking coating was firstly introduced. Then the optical and thermal properties of different types of window glazing were tested in the laboratory. Based on the experimental data, a combined daylight, thermal environment and building energy numerical model of a public rental housing was established to fully simulate the performance of different types of windows glazing. The results indicated that the heat blocking coating can reduce about $275.4 \mathrm{kWh}$ (14.4\%) electricity use per year compared to conventional clear window.
\end{abstract}

\section{KEYWORDS}

Window glazing, Heat blocking coating, Thermal performance, Window heat gain, Building energy use, Energy saving.

\section{INTRODUCTION}

Humans only feel well and comfortable within a narrow range of thermal conditions, but only a few places can provide this comfort for humans [1]. In most area, the climate condition cannot meet this comfort demand. Buildings can provide a comfortable space for human against the external conditions, but at the expense of massive energy consumption [2]. In general, more than $40 \%$ of primary energy is consumed by residential and commercial buildings in the world [3], in which a majority of the energy consumption comes from lighting, Heating, Ventilation, and Air-Conditioning (HVAC)

\footnotetext{
* Corresponding author
} 
[4]. Many researchers have found that there is a tremendous energy conservation potential in building's external envelope, especially external windows [5]. Most unwanted heat gain comes through the window by sunlight radiation and air infiltration [6]. Windows are the building's most vulnerable area for heat gain. Hence, it always plays an important role in reducing energy consumption for a room space [7].

To improve the thermal performance of external windows, various types of heat blocking glass have been developed to reduce the incoming solar heat gain [8]. The low-emissivity (low-E) glass [9] and the heat absorbing tinted glass [10] are the most commonly used heat blocking glass for buildings. Low-E glass has a microscopically transparent coating that can reflect the most of the near infrared light while letting the visible (VIR) light pass through windows. The sunlight is filtered allowing a wanted light to enter the building [11]. For the tinted glass, colour pigments are added during the float process of glass. The tinted coating blocks the infrared light into a room space by absorbing radiation energy, while it also reduces the visible light to some extent. The optical and thermal performance of the tinted glass has a close relationship with the colour material and the density of pigments [12].

These traditional types of heat blocking glass usually require special technology and high manufacturing cost, which severely limited their application only to commercial and high-grade residential buildings. However, the energy saving potential of general residential buildings is normally huge due to lack of energy conservation design and application of energy saving material, especially in the high-density city [13]. In Hong Kong, clear glass is normally used as the translucent material for external windows of residential buildings [14]. The clear glass has a high transmittance but low reflectance of solar radiation, which makes the windows as the greatest source of unwanted heat gain [15]. Additionally, either for low-E coated glass or for tinted glass, the coating process only can be done in glass's fabrication process, which means it is hard to transform a clear glass to heat blocking glass in late reformation [16]. To overcome the above limitations for traditional heat blocking glass, a wide waveband two-component transparent near infrared shielding coating combined Antimony doped Tin Oxide (ATO) and Cesium Tungsten Bronze $\left(\mathrm{Cs}_{0.33} \mathrm{WO}_{3}\right)$ nanomaterials, was developed [17]. ATO have been widely adopted for coatings owing to its Near Infrared (NIR) absorption properties and low cost [18]. Recently, $\mathrm{Cs}_{0.33} \mathrm{WO}_{3}$ has been proved a good NIR shielding material [19] due to its excellent optical and electrical properties [20]. At present, few studies were conducted on the energy performance of this newly developed heat blocking coating. Therefore, this paper focuses on the assessment of the overall energy performance of this coating.

In this paper, a brief introduction of the new coating will be given at first, then a systematic analysis has been conducted among the traditional heat blocking glasses and the glass with the new coating. Their physical properties are investigated, including the transmittance, reflectivity, absorptivity and heat conductivity. After the physical tests, based on a public rental housing in Hong Kong, a simulation model is established by EnergyPlus [21] and a series of simulation cases have been conducted. The simulation results will be reported and discussed at the end of this paper.

\section{HEAT BLOCKING COATING}

The heat blocking coating is created mainly by combined two types of nanoparticles dispersions, $\mathrm{Cs}_{0.33} \mathrm{WO}_{3}$ and ATO. The preparation of $\mathrm{Cs}_{0.33} \mathrm{WO}_{3}$ nanoparticles is based on a hydrothermal method. Tungsten hexachloride $\left(\mathrm{WCl}_{6}\right)$ powder and Cesium hydroxide hydrate $\left(\mathrm{CsOH} \cdot \mathrm{H}_{2} \mathrm{O}\right)$ powder are dissolved in absolute ethanol first and stirred to form a homogenous slurry. Then, the slurry is added by acetic acid with Polyvinylpyrrolidone (PVP) and put in the oven for $24 \mathrm{~h}$ at $220^{\circ} \mathrm{C}$. After cooling to room temperature, the $\mathrm{Cs}_{0.33} \mathrm{WO}_{3}$ nanoparticle is collected by centrifugation in ethanol. For the 
ATO nanoparticles, the preparation is conducted in the way of a hydrothermal method as well. Tin (IV) Chloride Pentahydrate $\left(\mathrm{SnCl}_{4} \cdot 5 \mathrm{H}_{2} \mathrm{O}\right)$, Antimony Trichloride $\left(\mathrm{SbCl}_{3}\right)$ and PVP are used as the raw materials to create the ATO. They are mixed in absolute ethanol, and then heated at $160{ }^{\circ} \mathrm{C}$ for $12 \mathrm{~h}$ to form the ATO particles. Finally, these two types of nanoparticles are dispersed (in deionized water) by ball mills for $12 \mathrm{~h}$. The weight ratio of $\mathrm{Cs}_{0.33} \mathrm{WO}_{3}$ and ATO is $70 \%$ and $30 \%$, respectively.

To examine the production of $\mathrm{Cs}_{0.33} \mathrm{WO}_{3}$ and ATO, X-ray Diffraction (XRD) test is conducted. The XRD patterns are illustrated in Figure 1. The strong and well-defined peaks in these two figures matched will with the standard pattern of $\mathrm{Cs}_{0.33} \mathrm{WO}_{3}$ (JCPDS 83-1334) and ATO (JCPDS 41-1445), which clearly suggests that these two nanoparticles have created successfully.
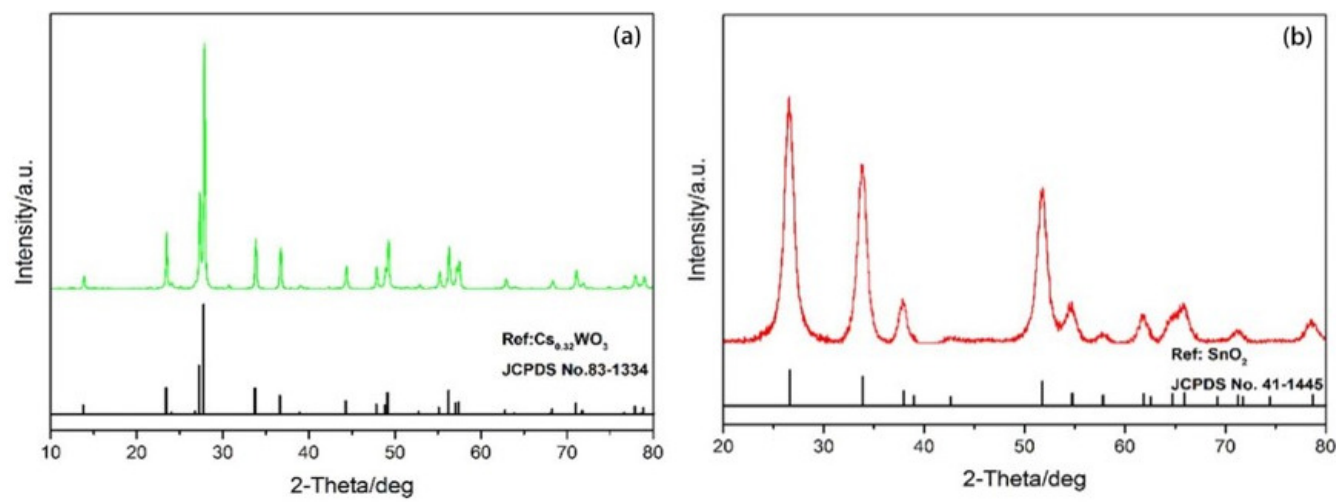

Figure 1. XRD patterns of: $\mathrm{Cs}_{0.33} \mathrm{WO}_{3}$ (a) and ATO (b)

\section{PROPERTIES OF WINDOW GLAZING}

The optical and thermal properties of the laminated low-E glass, the tinted glass, and the glass with heat blocking coating are tested in our laboratories, i.e. the transmittance, reflectivity, absorptivity, and heat conductivity. The test sample of the laminated low-E glass has the dimension of $30 \mathrm{~mm}$ (length) $\times 30 \mathrm{~mm}$ (width) $\times 10.5 \mathrm{~mm}$ (thickness). It consists of three parts:

- $5 \mathrm{~mm}$ clear anneal glass;

- 0.5 mm Polyvinyl Butyral (PVB);

- $5 \mathrm{~mm}$ low-E anneal glass.

The tinted glass sample and the glass with heat blocking coating have the same length and width with the low-E glass, but it is a single layer with the thickness of $6 \mathrm{~mm}$, as shown in Figure 2.
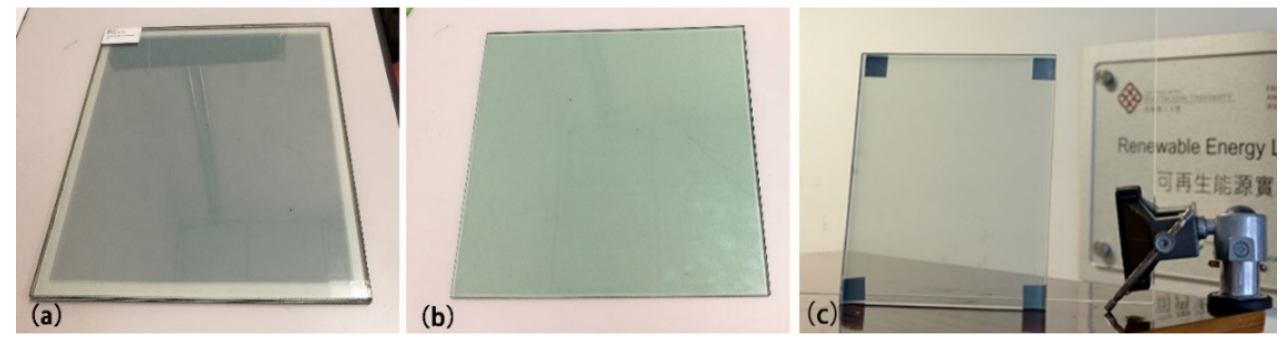

Figure 2. Photos of test samples: laminated low-E glass (a); tinted glass (b) and glass with heat blocking coating (c)

\section{Test methods}

Experiments were carried out to obtain the optical properties in full spectrum of sunlight (ultraviolet, visible, infrared spectroscopy) of the low-E glass, the tinted glass 
and the glass with the heat blocking coating. As a window, the transparency is most important, which has the direct relationship with the comfort of building occupants and the energy-saving performance of artificial lighting. Thus, the transmittance of the visible light of the glass would be tested. Additionally, the NIR ray whose wavelength ranges from $760 \mu \mathrm{m}$ to $2,600 \mathrm{~nm}$ makes a great contribution to the warming of the indoor environment. The near infrared transmittance, reflectance, and absorption of the different types of window glazing are tested. In addition, for the UV light, the blocking function of these test samples is also investigated. Samples are first cleaned to remove the dust particles and grease on the glass samples. Then, the test samples are placed into the spectrophotometer to measure those optical properties in full spectrum.

\section{Test results}

Part of the radiation reaching an object is absorbed and the remainder reflected. Usually, the absorbed radiation is converted to thermal energy, increasing the object's temperature. Manmade or natural systems, however, can convert part of the absorbed radiation into another form such as electricity or chemical bonds, as in the case of photovoltaic cells or plants. The proportion of reflected radiation is the object's reflectivity or albedo.

The full spectrum transmittance (wavelength ranging from $240 \mathrm{~nm}$ to 2,600 nm) of different types of window glazing are summarized in Figure 3. Clearly, the glass with the heat blocking coating has the best blocking effect of NIR. There is almost no light can transfer the glass when the wavelength is larger than 1,200 nm. But as a side-effect, the glass with heat blocking coating also shows the biggest drops in the transmittance of visible light with an average of 46.12\%. The Low-E glass and the tinted glass shows an acceptable visible light transmittance of $56.44 \%$ and $60.61 \%$, respectively.

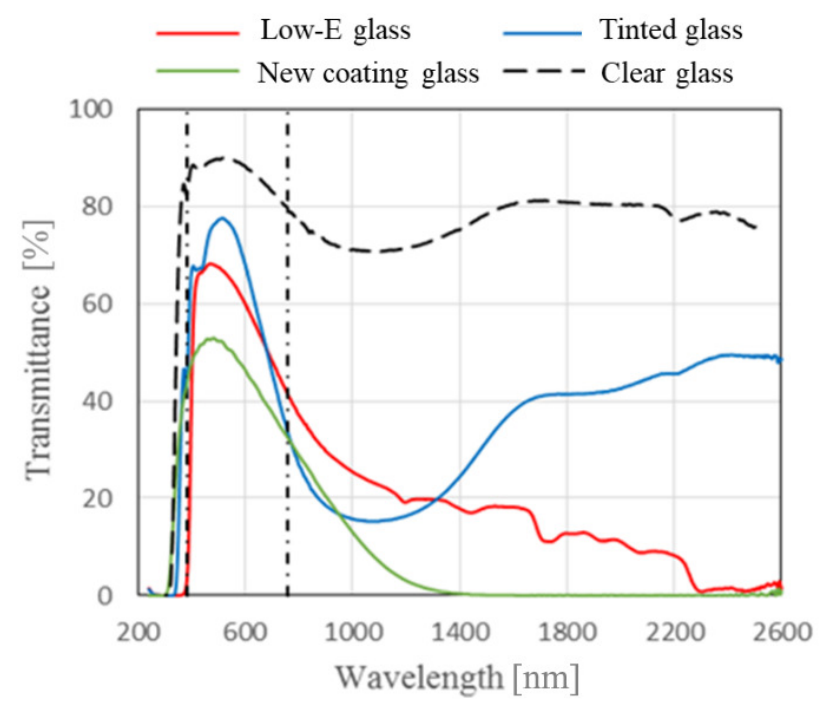

Figure 3. The transmittance of different types of window glazing

As shown in Figure 4, the low-E class has a strong reflectivity of NIR, but a lower absorptivity, which indicates the main mechanism of blocking heat for Low-E is to reflect the NIR thereby forming reflective thermal insulation. Different with the Low-E glass, the heat blocking mechanism of the tinted glass and the glass with heat blocking coating is due to the high absorptivity of NIR. But the new coating glass shows a better blocking performance with more than $90 \%$ of NIR successfully absorbed. Based on the experimental results, the calculated average optical properties of different types of window glazing are summarized in Table 1 . 

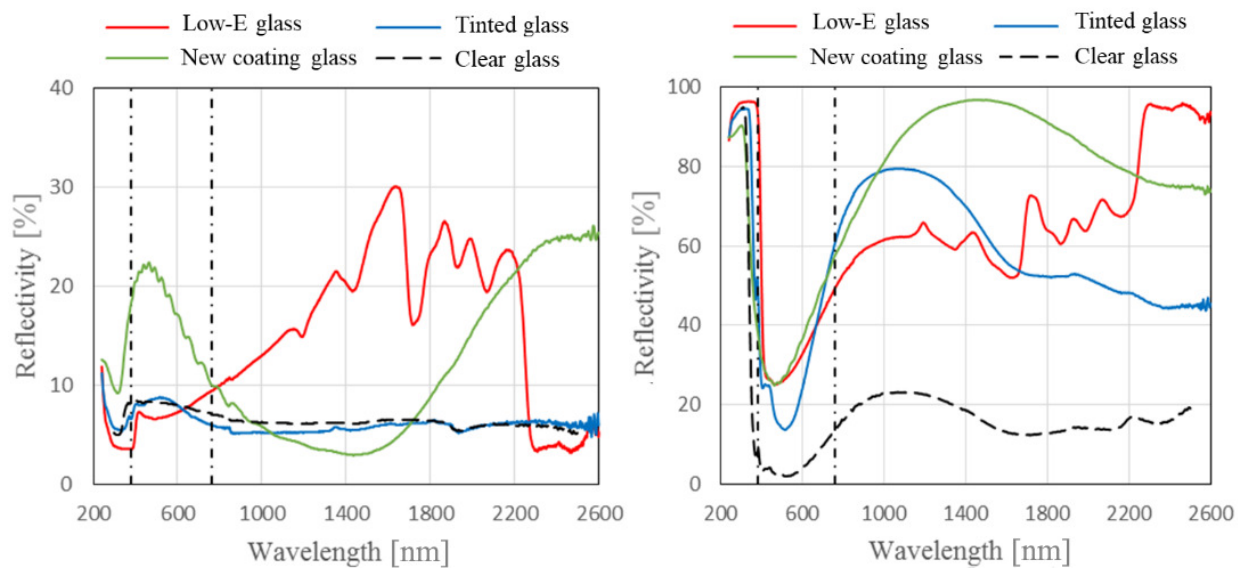

Figure 4 . The reflectivity and absorptivity of different types of window glazing

Table 1. Optical properties of different types of window glazing

\begin{tabular}{rccccc}
\hline Item & & Clear & Low-E & Tinted & Coated \\
\hline & UV & 43.91 & 0.24 & 8.48 & 10.38 \\
\multirow{2}{*}{ Transmittance [\%] } & VIS & 87.08 & 56.44 & 62.47 & 46.27 \\
& NIR & 76.94 & 14.99 & 34.30 & 4.22 \\
\hline \multirow{3}{*}{ Reflectivity [\%] } & UV & 6.41 & 6.17 & 6.55 & 12.14 \\
& VIS & 7.96 & 8.60 & 7.69 & 17.82 \\
& NIR & 6.14 & 27.88 & 5.79 & 11.53 \\
\hline \multirow{3}{*}{ Absorptivity [\%] } & UV & 49.68 & 93.35 & 84.97 & 84.25 \\
& VIS & 4.96 & 15.68 & 29.84 & 35.91 \\
& NIR & 16.92 & 57.13 & 59.91 & 84.25 \\
\hline
\end{tabular}

\section{NUMERICAL SIMULATION MODEL}

Three different types of scenario are simulated and investigated; a complete air-tight space, a naturally ventilated space without air-conditioning system, and an air-conditioned space. The second scenario assumed a naturally ventilated space, and windows are partially open (15\%) from March to November. An air-condoning system is adopted in the third scenario, and the system is operated during the work-off period from June to September.

\section{Geometry information}

To simulate the annual thermal performance and daylighting performance of the public rental housing in Hong Kong, a simulation room model has been created, as shown in Figure 5. It has the story height of $2.65 \mathrm{~m}$. The whole flat is regarded as a thermal zone, and five windows are simulated in this study. In this study, the biggest façade window is located on the south wall with the window dimension of $1,500 \mathrm{~mm}(L) \times 1,400 \mathrm{~mm}(H)$. The surface area of the south wall is equal to $9.09 \mathrm{~m}^{2}$, so the area ratio of window to wall is 0.23 . For the west surface, the window dimension is $1,320 \mathrm{~mm}(L) \times 1,400 \mathrm{~mm}(H)$ and the area ratio of window to wall is equal to 0.39 .
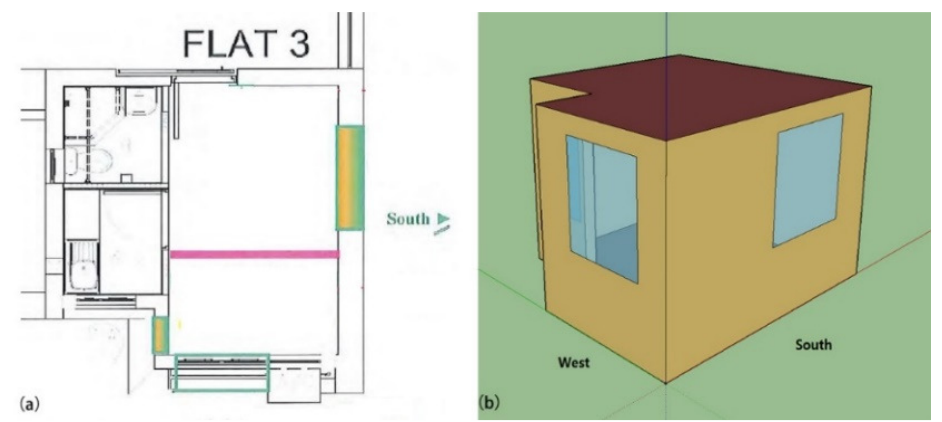

Figure 5. The floor plan (a) and the simulation model of a public rental housing (b) 


\section{Simulation setting}

According to the construction drawing, a three dimensional model is established using EnergyPlus. EnergyPlus is a building energy simulation software, which can simulate transient heat conduction, daylighting controls, on-site renewable power system and so on [22]. The results of EnergyPlus have been validated by previous studies [23]. A detailed whole building simulation with all floors at presence is not considered an effective approach. Therefore, in building performance simulation, the floor in the middle can represent the average of all typical floors. All the walls are the external walls, which directly contact with the outdoor environment except for the east wall which is assumed to be adiabatic. The meteorological data of Hong Kong acquiring from the Hong Kong Observatory is adopted in this simulation investigation [24]. The external wall consists of three layers, external insulating layer $(16 \mathrm{~mm}$ in thickness, $0.15 \mathrm{~W} / \mathrm{mK}$ in conductivity), brickwork (152 $\mathrm{mm}$ in thickness, $1.80 \mathrm{~W} / \mathrm{mK}$ in conductivity) and interior (25 $\mathrm{mm}$ in thickness, $1.80 \mathrm{~W} / \mathrm{mK}$ in conductivity). The overall energy performance simulation is divided into two parts: thermal performance and daylighting performance. The energy consumption of air-conditioning system has a direct relationship with the thermal performance of the simulated room. It is assumed that a window air conditioner with unlimited cooling capacity is installed. Additionally, daylighting model in EnergyPlus was used to simulate the daylighting performance of different glass of windows for comparison. The working plane ( $1 \mathrm{~m}$ above the floor) in the middle of the room was chosen as the daylight illuminance reference point, and then the electricity consumption from artificial lighting would also be simulated.

\section{RESULTS AND DISCUSSIONS}

Based on the simulation results, the energy performance of different types of window glazing under different scenarios is analysed.

\section{An airtight space without ventilation and air-conditioning system}

Figure 6 shows the temperature response when the simulation is a completely sealed room with different types of window glazing. It is not surprising that, in summer, the temperature keeps at a high level among all the cases. To an air-tight space, the heat energy, converted from solar radiation, is hard to release the room space. It can only dissipate by heat conduction, so the room temperature always higher than the outdoor. In addition, the temperature profiles clearly show that all the heat blocking glasses can prevent the temperature increase but with a limited effect. The coated glass performed best among the different types of heat blocking glasses brings down the maximum temperature from $41.98{ }^{\circ} \mathrm{C}$ (in the case of clear) to $38.86{ }^{\circ} \mathrm{C}$. For the case of the low-E glass and the tinted glass, the maximum room temperature is $39.38{ }^{\circ} \mathrm{C}$ and $39.79{ }^{\circ} \mathrm{C}$, respectively.
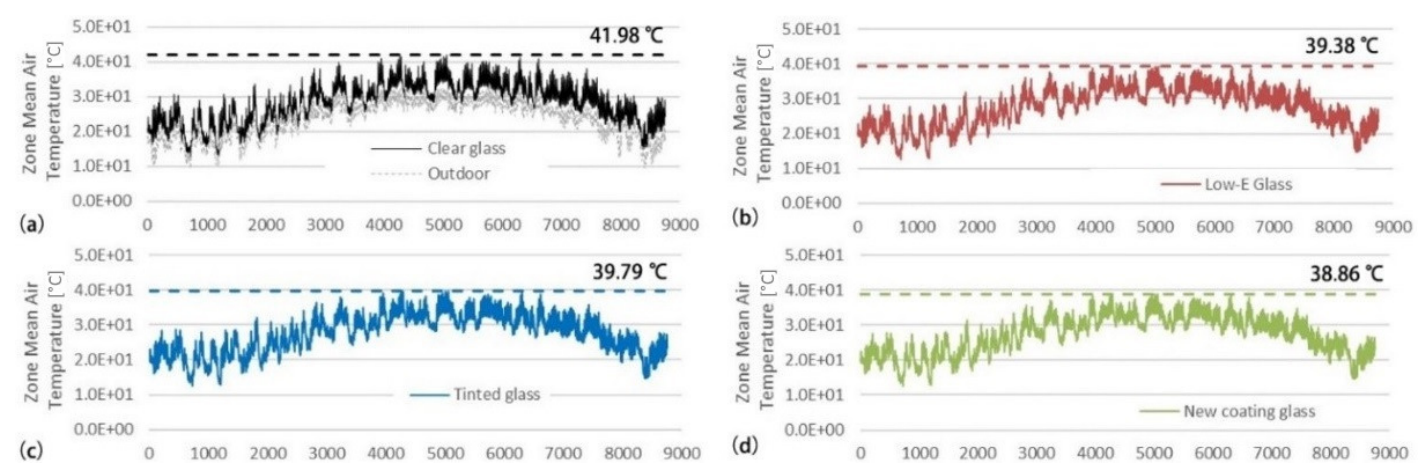

Figure 6. The hourly mean room air temperature: clear glass (a); low-E glass (b); tinted glass (c) and glass with heat blocking coating (an airtight space) (d) 
To more clearly compare the heat blocking effect of different types of window glazing, the total heat gain of the five windows in whole simulation year are summarized in Figure 7. Obviously, all the heat blocking glasses have an effective function in reducing the heat gain into the room space through the external windows. The coated glass has the best thermal performance, with an average reducing rate of $45.0 \%$ compared with the case of clear glass. For the cases of the low-E and the tinted glass, the average reduction is $35.6 \%$ and $30.4 \%$, respectively.

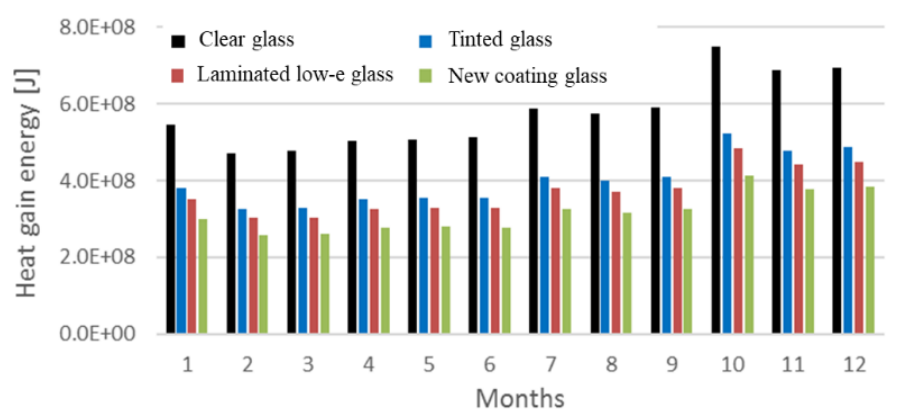

Figure 7. The total window heat gain energy of different types of window glazing (an airtight space)

A reference point is set at the centre of the room with a height of $1.5 \mathrm{~m}$ to monitor daylighting performance of different types of window glazing, and the collected data is illustrated in Figure 8. It is clearly shown that the heat blocking function is usually at the expense of the transmittance of visible light. Although the window with coated glass has a better thermal performance, its daylighting performances are worse than the clear glass. The artificial lighting system is triggered when natural light is insufficient, so it is not surprising that the room utilizing the coated glass consumes the most electricity energy among the four cases, as shown in Figure 9. But the increase ratio of energy consumption in the case of the coated glass is limited, only $3 \%$.

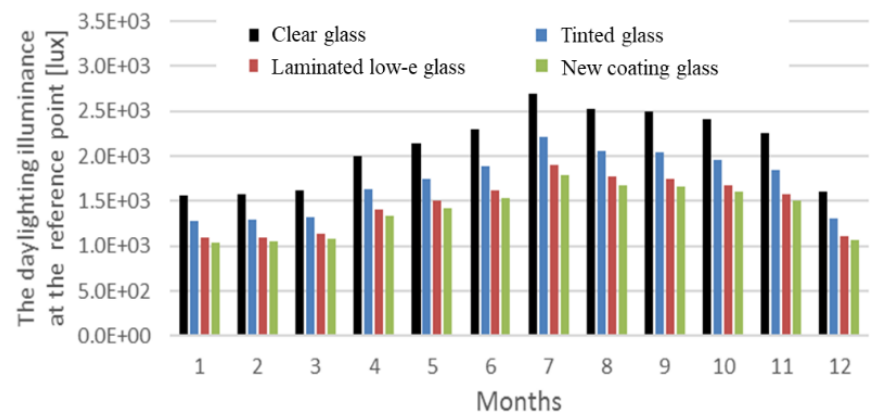

Figure 8. The daylighting illuminance at the reference point of different types of window glazing (an airtight space)

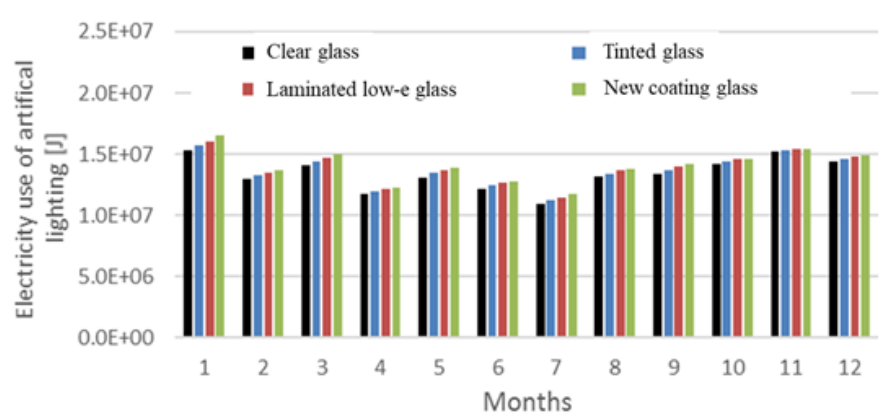

Figure 9. The monthly energy use of artificial lighting system (an airtight space) 


\section{A naturally ventilated space without air-conditioning system}

Infiltration and nature ventilation are simulated in this scenario. During the months from March to November, it is assumed that windows are closed from 7:00 to 20:00 on the weekdays and open for the rest. The open area is $15 \%$ of the window's area. For the month of January, February, and December, all the windows are assumed to be closed. The main results are summarized in the following paragraphs.

Figure 10 illustrates the simulated room temperature by applied different types of window glazing. As the effect of ventilation, the temperature decreases about $0.7^{\circ} \mathrm{C}$ in average, compared with the airtight scenario. The average temperature in June through September is considered as a reference temperature to evaluate the influence of different types of window glazing on the room temperature. The heat blocking glasses have a little influence on the room temperature. A maximum temperature difference of $0.54{ }^{\circ} \mathrm{C}$ occurs between the case with clear glass and the case with coated glass. Although the temperature change is not obvious, the heat blocking glasses have an effective help in controlling the high temperature of the housing. There are 2,280 hours per year when the room temperature is above $30.0^{\circ} \mathrm{C}$ in the case of clear glass, but for the case of coated glass, it is 1,975 hours per year. There are 2,042 hours per year, when the low-E is used as the window glazing.
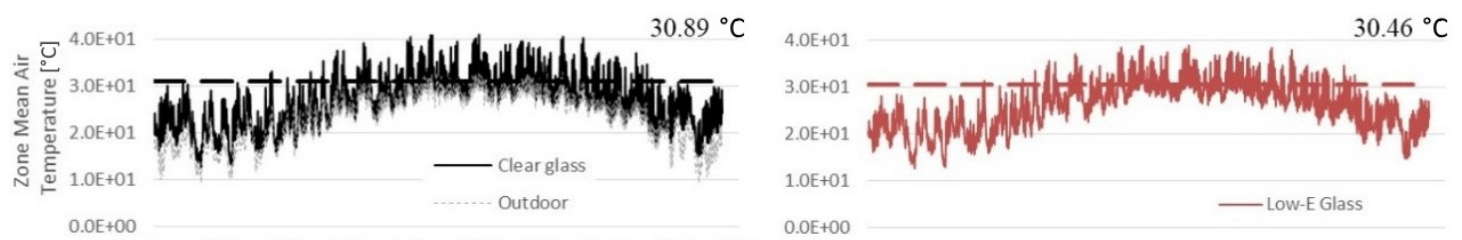

(a)

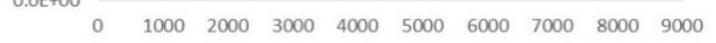

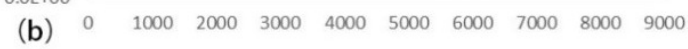
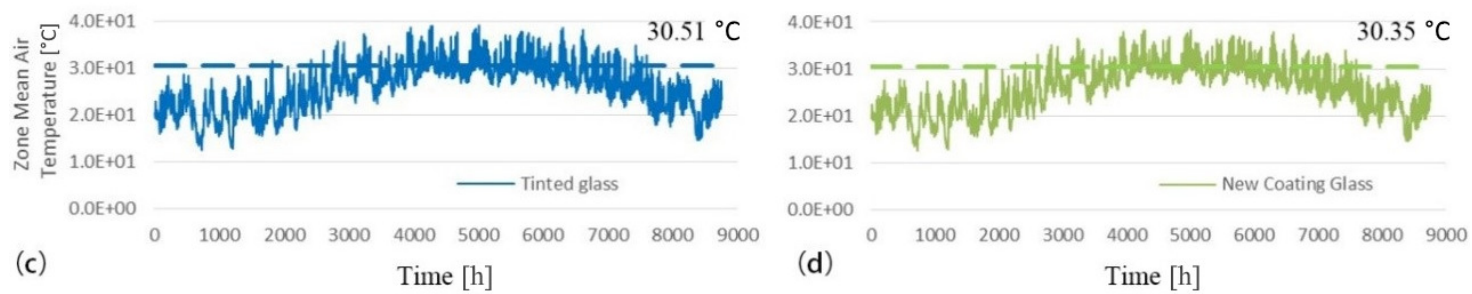

Figure 10. The hourly mean room air temperature: clear glass (a); low-E glass (b); tinted glass (c) and glass with heat blocking coating (a naturally ventilated space without air-conditioning) (d), the heat gain data of different windows is summarized in Figure 11 (similar to the first scenario, the heat gain energy of the heat blocking glass is much less than that of the clear glass, an average reducing rate of approximately $43.2 \%$ has been detected in the application of coated glass, and $34.6 \%$ of reduction is shown in the case of tinted glass)

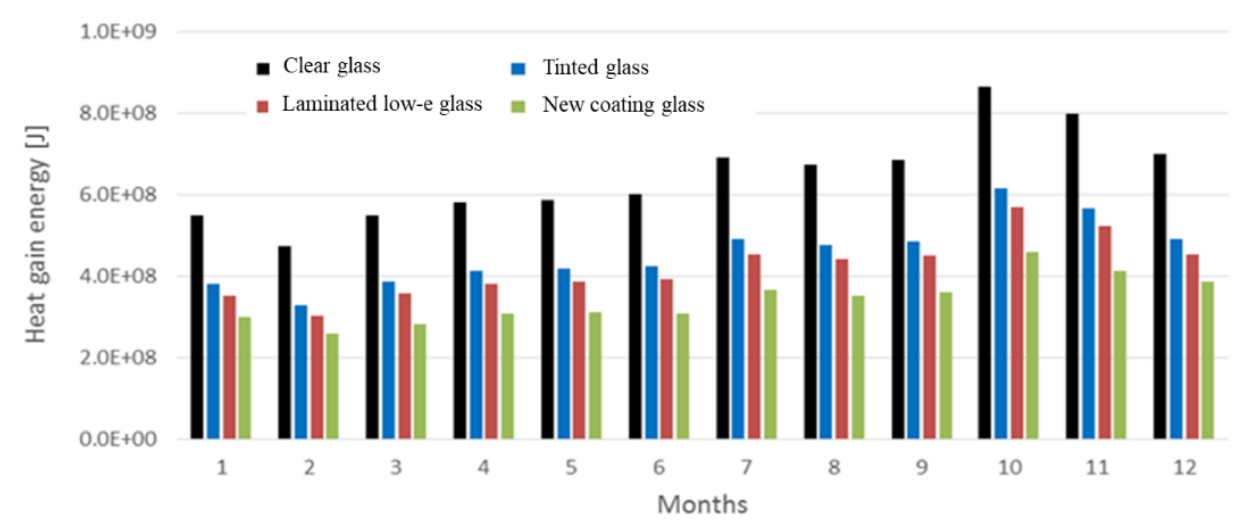

Figure 11. The total window heat gain energy of different types of window glazing (a naturally ventilated space without air-conditioning) 


\section{An air-conditioned space}

Generally, most of the residents (Hong Kong) prefer to choose window air-conditioner as their domestic cooling method. Thus, to investigate the influence of different types of window glazing on the housing applied air-conditioning system, an air-condoned space is simulated in this section. It is assumed that the system is operated during the period from June to September. In this period, the air-conditioning system is power off from 7:00 to 18:00 (operates in the remaining time) during the workdays (Monday to Friday), and operates in full-time during the weekends. The effect of infiltration is also simulated. The main results are summarized in the following parts.

Figure 12 presents the hourly room temperature response by applied different window glazing. It can be seen that the room temperature is maintained at $24{ }^{\circ} \mathrm{C}$ when the air-conditioning operates. The temperature increases quickly after the system shut down. The average temperature (June to September) of the clear glass is $26.56{ }^{\circ} \mathrm{C}$, which is $0.30{ }^{\circ} \mathrm{C}$ higher than that of coated glass.
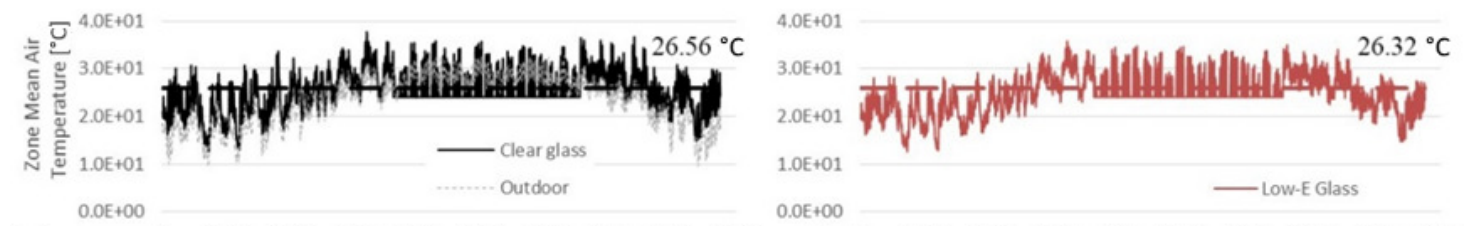

(a)

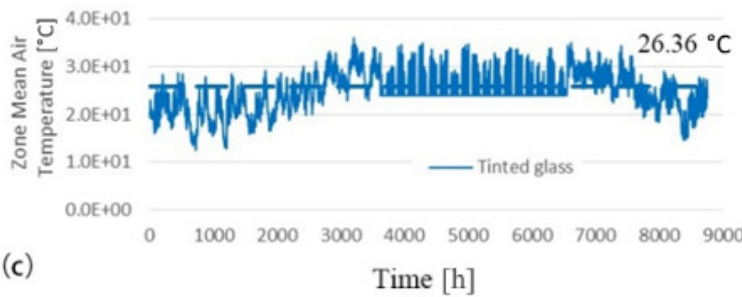

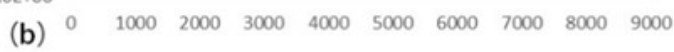

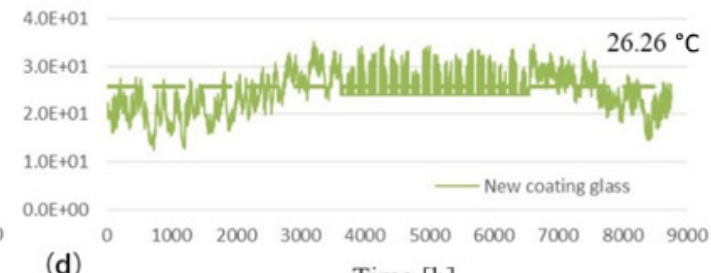

(d) Time [h]

Figure 12. The hourly mean room air temperature: clear glass (a); low-E glass; (b); tinted glass (c) and glass with heat blocking coating (an air-conditioned space) (d)

Figure 13 illustrates the total heat gain of the five windows when air-conditioning system is adopted. The coated glass is still the most efficient way in reducing the heat energy gain with the reducing ratio of $41.6 \%$. The average reducing ratio of the low-E glass and the tinted glass is $27.1 \%$ and $32.2 \%$, respectively.

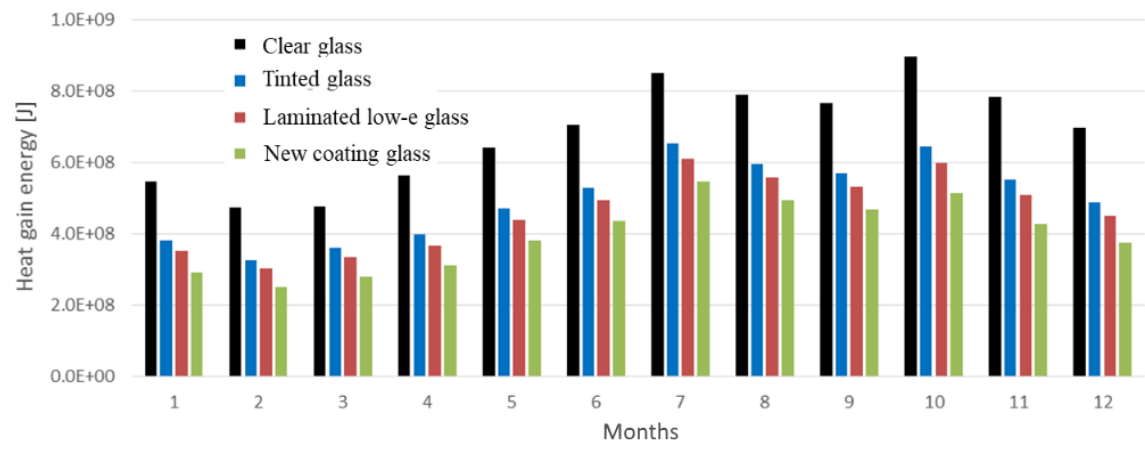

Figure 13. The window total heat gain energy of different types of window glazing (an air-conditioned space)

To analysis the overall energy performance of different heating blocking glasses, data are calculated and illustrated in Figure 14. When considered the thermal performance and daylighting performance of windows in a comprehensive way, the increase of energy 
consumption induced by lighting can be neglected. The housing using the coated glass as windows consumed the least energy, which was about $1,637.5 \mathrm{kWh}$ per year. Compared with the case of clear glass, this new type of window glazing can reduce about $275.4 \mathrm{kWh}$ electricity use per year due to its lower solar heat gain coefficient. The energy saving is more than $14.4 \%$. The electricity saving ratio of low-E glass and tinted glass is $11.5 \%$ and $9.4 \%$ respectively. Assuming the cost of electricity is $0.956 \mathrm{HKD}$ per degree, the cost saving by applied the new coating glass is $262.4 \mathrm{HKD}$ per year per housing. This saving expenditure may become several million when all the residential building utilize the coated glass as external windows, considering the high population density of Hong Kong.

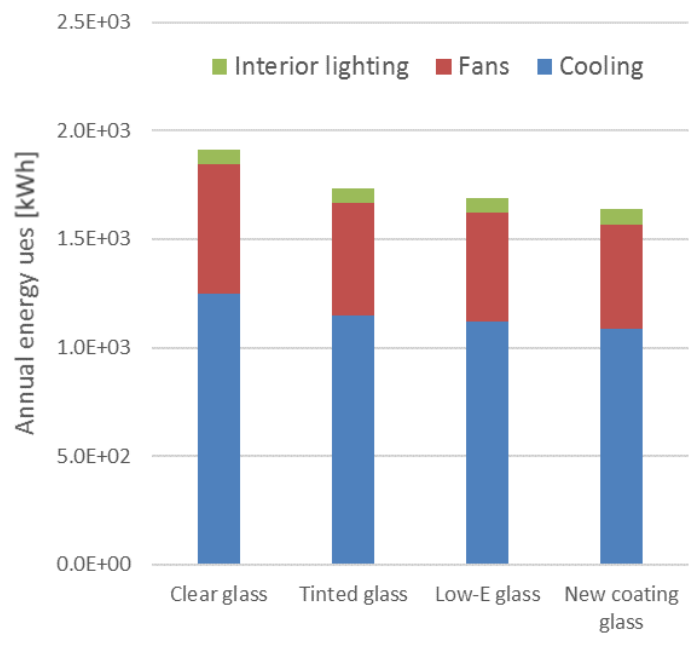

Figure 14. The annual energy use of air-conditioning and fan of different types of window glazing (an air-conditioned space)

\section{CONCLUSIONS}

In this paper, as a public rental housing as the application background, a comprehensive analysis in researching the performance of different types of window glazing are is conducted. The results show that the three types of heat blocking glass can improve the thermal environment of the rental housing:

- In all scenario, applying the heat blocking glasses can efficiently reduce the heat gain energy of the room, and decrease the heat load of the air-conditioned room. The glass with heat blocking coating always shows the best performance among the different types of window glazing. In scenario 1 and 2, an average reducing ratio is $45.0 \%$ and $43.2 \%$, respectively. For scenario 3 , the reducing ratio is $41.6 \%$;

- The heat blocking function of the glasses is at the expense of their daylighting performance. But artificial lighting system can compensate this shortage with a little price. The increase ratio of energy consumption in the case of the window with heat blocking coating is only $3 \%$;

- In the scenario with air-conditioning system, the windows with heat blocking coating can effectively minimize the energy consumption, which was about $1,637.5 \mathrm{~kW}$ per year. Compared with the case of clear glass, the heat blocking coating can reduce about $275.4 \mathrm{kWh}(14.4 \%)$ electricity use per year due to its lower solar heat gain characteristic. Assuming the cost of electricity is $0.956 \mathrm{HKD}$ per degree, the cost saving by applied the new coating glass is 262.4 HKD per year.

\section{ACKNOWLEDGEMENT}

The work described in this paper was supported by the Natural Science Foundation of Shandong Province, China (NO. ZR2016EEB28) and a grant from Shandong Key R\&D Program (NO.2017GGX40117). 


\section{REFERENCES}

1. Rupp, R. F., Vásquez, N. G. and Lamberts, R., A review of Human Thermal comfort in the built Environment, Energy and Buildings, Vol. 105, pp 178-205, 2015, https://doi.org/10.1016/j.enbuild.2015.07.047

2. Yang, L., Yan, H. and Lam, J. C., Thermal comfort and Building Energy consumption implications - A review, Applied Energy, Vol. 115, pp 164-173, 2014, https://doi.org/10.1016/j.apenergy.2013.10.062

3. Anderson, J. E., Wulfhorst, G. and Lang, W., Energy analysis of the built Environment A review and outlook, Renewable and Sustainable Energy Reviews, Vol. 44, pp 149-158, 2015, https://doi.org/10.1016/j.rser.2014.12.027

4. DeForest, N., Shehabi, A., Selkowitz, S. and Milliron, D. J., A comparative Energy analysis of three Electrochromic glazing Technologies in Commercial and Residential Buildings, Applied Energy, Vol. 192, pp 95-109, 2017, https://doi.org/10.1016/j.apenergy.2017.02.007

5. Hemsath, T. L. and Bandhosseini, K. A., Sensitivity analysis evaluating basic Building Geometry's effect on Energy use, Renewable Energy, Vol. 76, pp 526-538, 2015, https://doi.org/10.1016/j.renene.2014.11.044

6. Tian, C., Chen, T., Yang, H. and Chung, T. M., A generalized Window Energy rating System for typical Office Buildings, Solar Energy, Vol. 84, No. 7, pp 1232-1243, 2010, https://doi.org/10.1016/j.solener.2010.03.030

7. Zhang, W. and Lu, L., Energy Performance and Heat transfer characteristics of Photovoltaic double Skin Facades (PV-DSFs): A review, Sustainable Energy \& Fuels, Vol. 1, No. 7, pp 1502-1515, 2017, https://doi.org/10.1039/C7SE00175D

8. Han, K. and Kim, J. H., Reflectance modulation of transparent Multilayer thin Films for Energy efficient Window Applications, Materials Letters, Vol. 65, No. 15-16, pp 2466-2469, 2011, https://doi.org/10.1016/j.matlet.2011.05.006

9. Zhang, X. and Pramanik, D., U.S. Patent No. 8,859,093, U.S. Patent and Trademark Office, Washington, D. C., USA, 2014.

10.Gulotta, J. A. and Shelestak, L. J., U.S. Patent No. 5,240,886, U.S. Patent and Trademark Office, Washington, D. C., USA, 1993.

11.Chiba, K., Takahashi, T., Kageyama, T. and Oda, H., Low-emissivity Coating of amorphous Diamond-like Carbon/Ag-alloy Multilayer on Glass, Applied Surface Science, Vol. 246, No. 1-3, pp 48-51, 2005, https://doi.org/10.1016/j.apsusc.2004.10.046

12.Osuagwu, U. L. and Ogbuehi, K. C., UV-vis Light transmittance through tinted Contact Lenses and the Effect of Color on Values, Contact Lens and Anterior Eye, Vol. 37, No. 3, pp 136-143, 2014, https://doi.org/10.1016/j.clae.2013.09.004

13.Chen, X., Yang, H. and Zhang, W., A Comprehensive Sensitivity study of Major passive Design Parameters for the Public rental housing development in Hong Kong, Energy, Vol. 93, Part 2, pp 1804-1818, 2015, https://doi.org/10.1016/j.energy.2015.10.061

14.Chen, X. and Yang, H., Combined Thermal and Daylight analysis of a typical Public rental housing development to fulfil Green Building guidance in Hong Kong, Energy and Buildings, Vol. 108, pp 420-432, 2015, https://doi.org/10.1016/j.enbuild.2015.09.032

15.Zhang, W., Lu, L., Peng, J. and Song, A., Comparison of the overall Energy Performance of semi-transparent Photovoltaic Windows and common Energy-efficient Windows in Hong Kong, Energy and Buildings, Vol. 128, pp 511-518, 2016, https://doi.org/10.1016/j.enbuild.2016.07.016

16.Cuce, E. and Riffat, S. B., A State-of-the-art review on innovative glazing Technologies, Renewable and Sustainable Energy Reviews, Vol. 41, pp 695-714, 2015, https://doi.org/10.1016/j.rser.2014.08.084

17.Xu, X., Zhang, W., Hu, Y., Wang, Y., Lu, L. and Wang, S., Preparation and overall Energy performance assessment of wide Waveband two-component transparent NIR 
shielding Coatings, Solar Energy Materials and Solar Cells, Vol. 168, pp 119-129, 2017, https://doi.org/10.1016/j.solmat.2017.04.032

18.Li, Y. Q., Wang, J. L., Fu, S. Y., Mei, S. G., Zhang, J. M. and Yong, K., Facile Synthesis of Antimony-doped Tin Oxide Nanoparticles by a Polymer-pyrolysis Method, Materials Research Bulletin, Vol. 45, No. 6, pp 677-681, 2010, https://doi.org/10.1016/j.materresbull.2010.03.003

19.Lee, K. S., Seo, D. K. and Whangbo, M. H., Electronic Band Structure Study of the anomalous electrical and superconducting Properties of Hexagonal Alkali Tungsten Bronzes $\mathrm{A}_{\mathrm{x}} \mathrm{WO}_{3}(\mathrm{~A}=\mathrm{K}, \mathrm{Rb}, \mathrm{Cs})$, Journal of the American Chemical Society, Vol. 119, No. 17, pp 4043-4049, 1997, https://doi.org/10.1021/ja964455t

20.Azimirad, R., Goudarzi, M., Akhavan, O. and Moshfegh, A. Z., The Effect of heating Time on growth of $\mathrm{Na}_{x} \mathrm{WO}_{3}$ Nanowhiskers, Vacuum, Vol. 82, No. 8, pp 821-826, 2008, https://doi.org/10.1016/j.vacuum.2007.11.012

21.Crawley, D. B., Lawrie, L. K., Winkelmann, F. C., Buhl, W. F., Huang, Y. J., Pedersen, C. O., Strand, R. K., Liesen, R. J., Fisher, D. E., Witte, M. J. and Glazer, J., EnergyPlus: Creating a New-generation Building Energy Simulation Program, Energy and Buildings, Vol. 33, No. 4, pp 319-331, 2001, https://doi.org/10.1016/S0378-7788(00)00114-6

22.Energy Plus Energy Simulation Software, http://energyplus.net, [Accessed: 08-June-2018]

23.Zhou, Y. P., Wu, J. Y., Wang, R. Z., Shiochi, S. and Li, Y. M., Simulation and experimental validation of the Variable-refrigerant-volume (VRV) Air-conditioning System in EnergyPlus, Energy and Buildings, Vol. 40, No. 6, pp 1041-1047, 2008, https://doi.org/10.1016/j.enbuild.2007.04.025

24.Hong Kong Observatory, http://www.hko.gov.hk/contentc.htm, [Accessed: 08-June-2018] 